\section{An ideal Universe?}

\section{A. Rupert Hall}

Descartes' Metaphysical Physics. By Daniel Garber. University of Chicago Press: 1992. Pp. 389. \$60, £47.95 (hbk); \$23.95, £19.95 (pbk).

BY giving a mighty kick to a stone, that British arch-empiricist Samuel Johnson proved to his own satisfaction the reality of matter. The pain in his foot caused by striking a large mass assured the sensational existence of solid bodies. By contrast, the refounder of idealism in Europe, René Descartes, went to great intellectual lengths to prove by reasoning alone that the stone we seem to see or feel is not an illusion; to Descartes, Johnson's sore toe demonstrated only his mental awareness of the stone, not its real existence. In Descartes' view, our sense of something is no demonstration of its reality, for bodies perceived by our senses and bodies truly existing are not the same thing - as any physical scientist will agree. Galileo made the same distinction more simply by his famous separation of the primary from the secondary qualities of bodies, a distinction echoed by Boyle and Locke.

To a modern scientist, as indeed to Laplace, it may seem strange that Descartes deduced the reality of 'bodies' (the Universe) from a logical demonstration of the existence of an active God, rather than vice versa (which was the way of the natural theologians Henry More, John Ray and Isaac Newton). In Cartesian metaphysics, the existence and rational structure of the Universe were warranted by our subjective knowledge of its Creator, who cannot deceive. Descartes does not seem to deal with the position that, regardless of whether the Universe is real or a dream, the Universe must be of equal interest to us, because we are conscious of inhabiting it and being profoundly affected by it. Having proved to his own satisfaction that 'bodies' are real, Descartes accepted the consequence that the human mind can form a true image of them, although this must be very different from our first naive impressions of the composition of things.

A most important contribution by Descartes to the development of modern physics was his rejection of the 'qualities' of things as real and basic; he preferred instead to reduce them to matter and the size, shape and motions of its constituent particles. As Daniel Garber rightly points out, Descartes was indebted for this notion to the Greek atomist tradition, which was revived in the sixteenth

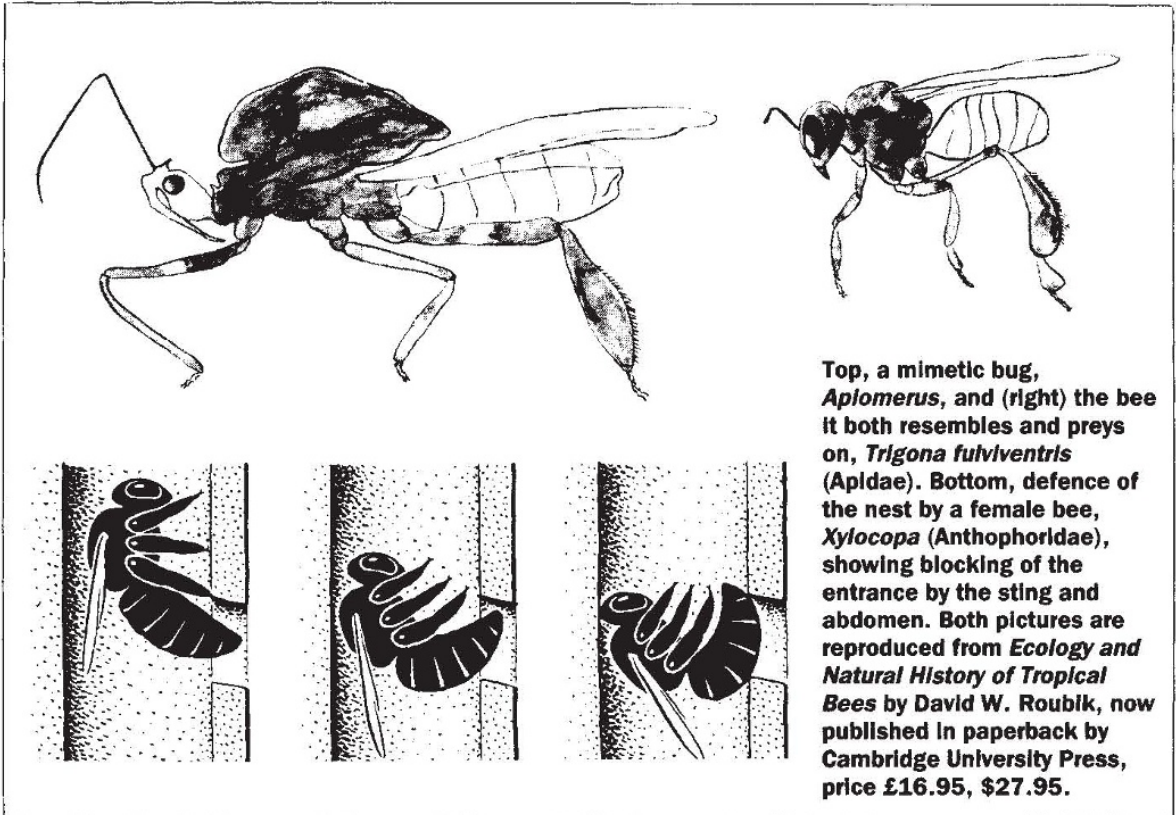

century and expounded as a valid philosophy of nature by Pierre Gassendi. Descartes' corpuscular philosophy was the more successful, not only because it was carefully purged of anti-Christian overtones and was more detailed and imaginative in its kinematics, but also because it was creatively linked by Descartes to the mathematical treatment of physical puzzles such as the refraction of light, and the rainbow. In turn, Descartes' system was the antecedent for later mechanist philosophies such as those of Huygens and Leibniz, while Newton (during his creative middle life, at any rate) preferred the atoms-and-thevoid concept which he took (ultimately) from Gassendi, enriching and transforming this by his own mechanism of forces.

After the establishment of the reality of matter, the next most important issue for Descartes was the inevitability of motion, for the movement of material particles was, in his view as in that of the atomists, the origin of all phenomena. Motion came originally only from God, and therefore could be neither lessened nor enlarged in the duration of the Creation. It could only be transferred from particle to particle, from gross body to gross body, and solely by the impact of one upon the other. Here, at the very heart of his system, Descartes encountered great difficulties that he failed to overcome - although he himself admitted no such failure. For example, in dealing with the motion of light, he treated it now as a particle travelling from a source, at other times as a pressure in a particulate medium. This, and other curious procedures, was justified in Descartes' mind by the contention that a potential motion can be equated to an actual movement. (Thus a particle under pressure in some direction will move as soon as its motion is unobstructed.) Descartes' ideas led him to formulate an incorrect - indeed, almost absurd - theory of collisions, soon revealed as such by others. Garber is perhaps too kind to Cartesian mechanics, and to Descartes' confidence that the rival, geometrical ideas of movement stemming from Galileo were useless.

For all that, Garber's analysis of Descartes' a priori account of the Universe is acute, learned and detailed. Descartes' intellectual debt to Isaac Beeckman of Dordrecht from the discussions the two men had in 1618 is fully acknowledged. Garber's analysis is not always easy to follow: the subject is difficult and technical. Moreover, the book combines an unfolding of Descartes' mature system (found chiefly in the Latin Principles of Philosophy, 1644) with an investigation of its evolution from the draft Le Monde (early 1630s); the reader has therefore to follow a critical investigation of Descartes' thought about bodies and motion while also taking account of the changes in his thought. That said, the book is very well argued and is founded upon a complete familiarity with Descartes' writings. As the use of the adjective 'metaphysical' in the title indicates, this is wholly a philosophical discussion, which does not extend to consideration of the connections between Descartes' reconstruction of the bases of thinking about nature, and the two wonderful optical treatises of 1637 (Dioptrique and Météores) - or indeed to the transition in the Principles itself from these foundations to Descartes' specific, hypothetical corpuscular mechanisms for the explanation of phenomena.

A. Rupert Hall, is at 14 Ball Lane, Tackley, Oxford OX5 3AG, UK. 